\title{
Atypical Presentation of Primary Ewing's Sarcoma
}

\begin{abstract}
Ewing's sarcoma is the second most common bone tumor in children and adolescents. Its annual incidence is 0.6 /million total population worldwide, and in some populations in India, its incidence can account for $15 \%-19.4 \%$ of the primary bone tumors. Ewing's sarcoma is a highly malignant round cell tumor, affecting the metadiaphyseal and the diaphyseal regions of the long bones. Spine involvement, as a primary focus in Ewings sarcoma is uncommon, but when present, usually affects the sacrum. Origin from non sacral region is extremely rare. We report a case of acute onset of paraplegia progressing to quadriplegia in a child with metastatic involvement of the spine, primary focus being the nonsacral spine which is inherently challenging to an early diagnosis. Ewing's sarcoma though has improved survival with chemotherapy and radiotherapy, primary spine focus has poor prognosis.

Keywords: Acute onset paraplegia, cord compression, Ewing's sarcoma, malignant bone tumors of childhood, spine involvement
\end{abstract}

\section{Introduction}

Ewing's sarcoma is the second most common bone tumor in children and adolescents with its incidence being $15 \%{ }^{[1,2]}$ of the primary bone tumors.

Ewing sarcoma, a malignant tumor, though has improved survival postadvent chemotherapy, certain primary sites of involvement especially the spine carry poor prognosis. Nonsacral origin of primary Ewing's sarcoma has an inherent low survival, which is further complicated by its rarity and late presentation presenting challenges to diagnosis and treatment.

\section{Case Report}

A 16-year-old boy presented to us with history of acute onset of weakness of bilateral lower limbs progressing over $24 \mathrm{~h}$. There was no history of prior trauma or associated fever. On examination, there was weakness of both lower limbs with extensor plantar response. Magnetic resonance imaging spine revealed multiple space-occupying lesions of the spine with loss of cervical lordosis and significant spinal cord compression at the thoracic D4-D7 level [Figures 1 and 2].

Emergency decompression of the spinal cord was done with laminectomy at D4-D7 level and excision of the thoracic lesion.

This is an open access journal, and articles are distributed under the terms of the Creative Commons Attribution-Non Commercial-ShareAlike 4.0 License, which allows others to remix, tweak, and build upon the work non-commercially, as long as appropriate credit is given and the new creations are licensed under the identical terms.

For reprints contact: reprints@medknow.com
Histopathology of the lesion showed small round cell tumor suggestive of primitive neuroectodermal tumor of the bone/ Ewing's sarcoma. Immunohistochemistry confirmed the diagnosis of Ewing's sarcoma. His lower limb weakness after the decompressive laminectomy did not show any improvement, and over the next 2 days, he further progressed to develop upper limb weakness as well. Local radiotherapy was started followed by adjuvant chemotherapy with four-drug regimen. However, despite this multidisciplinary approach, he succumbed to the illness after the first course of chemotherapy, within 2 months of the onset of symptoms.

\section{Discussion}

Ewing's sarcoma accounts for $15 \%-19 \%$ of primary bone tumors mainly occurring between 10 and 20 years of age and affecting males more than females. ${ }^{[3]}$

Ewing's sarcoma is a tumor of the growing bones, common location being the metaphyseal plate and the diaphyseal regions of the long bones. Long bone involvement classically presents with local pain and swelling. It rarely involves the spine with a $4 \%$ incidence; ${ }^{[4]}$ where then, the most common location is that of the sacrum. Nonsacral location is rare, with silent multifocal involvement of the spine being rarer. In these cases, features of

How to cite this article: Jeniffer NV, Panduranga A, Karunakara BP. Atypical presentation of primary Ewing's sarcoma. Indian J Med Paediatr Oncol 2018;39:398-9.
Nancy V Jeniffer, Arpitha Panduranga, BP Karunakara

Department of Paediatrics, M S Ramaiah Medical College and Hospital, Bengaluru, Karnataka, India
Address for correspondence: Dr. Nancy V Jeniffer, Assistant Professor, Department of Paediatrics, M S Ramaiah Medical College and Hospital, Bengaluru, Karnataka, India. E-mail: dollyvijiyan@yahoo.com

Access this article online Website: www.ijmpo.org DOI: 10.4103/ijmpo.ijmpo_71_17 Quick Response Code:

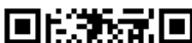




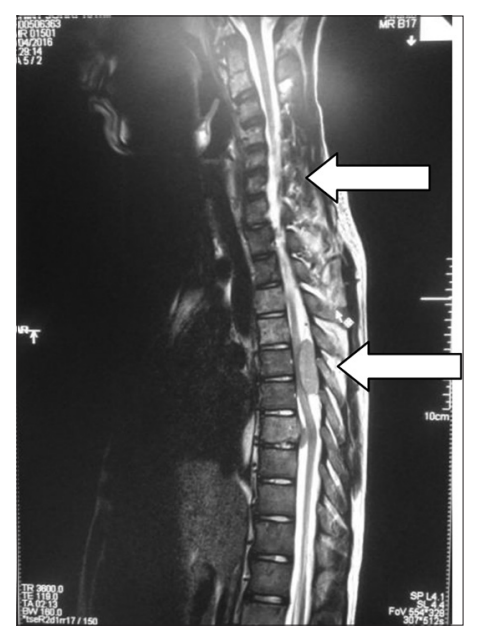

Figure 1: Magnetic resonance imaging T2-weighted sagittal section of the spine showing multiple lesions with Upper left arrow - cervical spine involvement from $\mathrm{C} 3$ to $\mathrm{C} 7$ spine with reversal of lordosis. Lower left arrow - posterior thoracic lesion causing significant cord compression

spinal cord compression usually occur late in the course of the disease and predispose to unfavorable outcomes due to delayed diagnosis.

This child presented in the later stages of the disease with metastatic lesions of the spine with compression and cord changes at various levels. He was asymptomatic before the onset of his weakness of lower limbs sparing nonspecific complaints of fatigue and neck pain after long hours of reading.

Multidisciplinary approach in the treatment involving surgical decompression, chemotherapy, and radiotherapy are necessary to improve chances of survival. ${ }^{[5]}$

Laminectomy is an effective approach for tumors invading spinal cord from paravertebral soft tissues through the intervertebral foramen as was done in this case. Anterior decompression is the preferred intervention for tumors involving spinal cord from the body of the vertebra.

Radiotherapy is administered in cord-tolerant low doses and should always follow decompression in such cases to prevent posttreatment edema of the spinal cord and worsening of deficits.

Although chemotherapy has advanced in providing up to $75 \%$ survival in localized lesions, metastatic lesions still do have poor prognosis. ${ }^{[6]}$ Chemotherapy which is usually given in three-four-drug regimen is to help restrict further spread, prevent micrometastasis, and also decrease the bulk of the tumor. The four-drug chemotherapy classically followed consists of vincristine sulfate, dactinomycin, and cyclophosphamide and doxorubicin hydrochloride. ${ }^{[7]}$

The other differential diagnosis of a small round cell bone tumor includes Ewing's sarcoma, rhabdomyosarcoma, neuroblastoma, malignant lymphoma, and primitive neuroectodermal tumor of bone. ${ }^{[7]}$

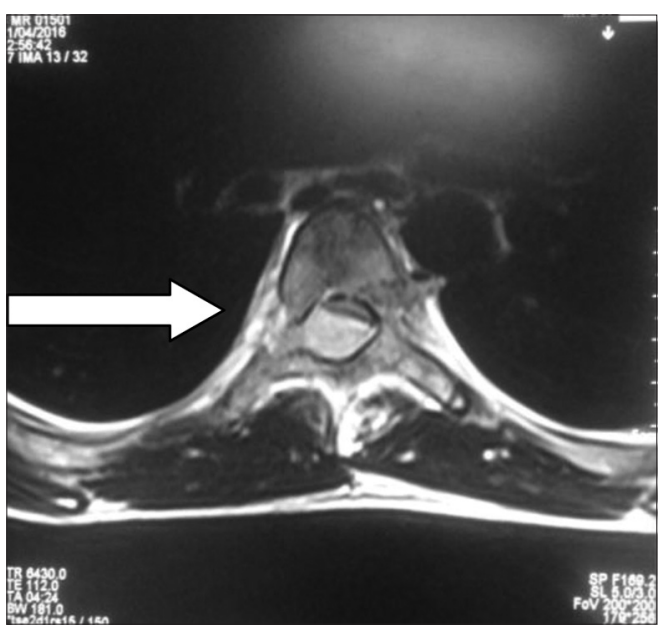

Figure 2: Axial section T2-weighted magnetic resonance imaging spine showing hyperintense extradural extramedullary lesion (right arrow) in the spinal canal of level D4-D5 extending to the pedicle of the vertebra

Ewing's sarcoma/malignancy should be considered in the differential diagnosis of any child who presents with acute onset of paraplegia due to its poor outcome. Spine involvement, as a primary focus in Ewings sarcoma is uncommon, but when present, usually affects the sacrum. Origin from non sacral region is extremely rare. Multidisciplinary approach is crucial to good prognosis and survival.

\section{Financial support and sponsorship}

Nil.

\section{Conflicts of interest}

There are no conflicts of interest.

\section{References}

1. Burchill SA. Ewing's sarcoma: Diagnostic, prognostic, and therapeutic implications of molecular abnormalities. J Clin Pathol 2003;56:96-102.

2. Rao VS, Pai MR, Rao RC, Adhikary MM. Incidence of primary bone tumours and tumour like lesions in and around Dakshina Kannada district of Karnataka. J Indian Med Assoc 1996;94:103-4.

3. Jawad MU, Cheung MC, Min ES, Schneiderbauer MM, Koniaris LG, Scully SP, et al. Ewing sarcoma demonstrates racial disparities in incidence-related and sex-related differences in outcome: An analysis of 1631 cases from the SEER database, 1973-2005. Cancer 2009;115:3526-36.

4. Ebb DH, Green DM, Shamberger RC, Tarbell NJ. Solid tumours of childhood. In: DeVita VT Jr., Hellman S, Rosenberg SA, editors. Cancer Principles and Practice of Oncology. Philadelphia: Lippincott; 2005. p. 1919-23.

5. Kannan KK, Sundarapandian RJ, Surulivel VJ. Unusual presentation of a primary Ewing's sarcoma of the Spine with paraplegia: A case report. J Clin Diagn Res 2015;9:RD01-3.

6. Ludwig JA. Ewing sarcoma: Historical perspectives, current state-of-the-art, and opportunities for targeted therapy in the future. Curr Opin Oncol 2008;20:412-8.

7. Balamuth NJ, Womer RB. Ewing's sarcoma. Lancet Oncol 2010;11:184-92. 